\title{
Hydrodynamic Analysis and Modeling of Nozzle for Particle Jet Impact on Rock Broken
}

\author{
Xiao-ze CHENG ${ }^{1,2}$, Fu-shen REN ${ }^{1,}$, and Tian-cheng FANG ${ }^{1}$ \\ ${ }^{1}$ College of Mechanical Engineering, Northeast Petroleum University, Daging 163318, China \\ ${ }^{2}$ China National Petroleum Corporation, Beijing, 100724, China \\ ${ }^{*}$ Corresponding author
}

Keywords: Particle jet, Nozzle, Rock broken, Mathematical model, Simulation.

\begin{abstract}
Particle impact drilling is a kind of rock breaking method, that high speed metal particles and fluid were given priority to be used to jointly break rock, and mechanical drill bits were supplemented. It is an effective means to solve the hard and abrasion-resistant drilling problems in deep and ultra-deep well drilling. Accelerate process of the particle in the fluid are analyzed, In view of the cone type nozzle, the equations of fluid motion and acceleration simulation of particle were established, and resolved the mathematical model, using Fluent software simulation platform, simulation verification was performed for the acceleration of particles and fluid in a straight cone nozzle. The calculation results were identical to the simulation results. It proved the mathematical model is correct. The results can be used to determine rock parameters for particle jet impact.
\end{abstract}

\section{Introduction}

Particle impact drilling is a kind of rock breaking method, that high speed metal particles and fluid were given priority to be used to jointly break rock, and mechanical drill bits were supplemented [1]. It is an effective means to solve the hard and abrasion-resistant drilling problems in deep and ultra-deep well drilling. Instantaneous contact -impact stress will produce when high speed metal particles hit rock because of the impact of the particles on a very small contact area. When the instantaneous stress exceeds compressive strength of extremely hard rock, the particles embedded and broken rock, tensile stress and shear stress can produce in the contact -impact region boundary [2]. Due to the tensile strength of the rock is only 1/16 1/80 of its compressive strength and the shear strength is only $1 / 8 \sim 1 / 15[3,4]$, dominant crack and micro cracks recessive will form when the tensile stress and shear stress were more than the limit of rock tensile and shear strength [5]. In addition, stress wave of the impacts would be spread to all around based on the impact sites as the center. The rock near the point of impact present the characteristics of the plastic flow by acting under the great pressure, rock cracks under tensile stress due to the propagation of stress wave. Produced a lot of broken rock debris in the joint action of high frequency and high velocity of particles, so as to improve the speed of rock breaking for underlying rock hard and abrasion

\section{Structure and working principle of particle jet impact rock experiment device Section Headings}

Particle jet impact rock testing device is developed [6], as shown in Fig. 1. High pressure mud power system is mainly composed of a $110 \mathrm{kw}$ power of mud pump, which can provide testing device with $32 \mathrm{Mpa}$ and $10.8 \mathrm{~m} 3 / \mathrm{h}$ water power; Particle mixing device is mainly completed the metal particles evenly mixed to the pipeline of high pressure water according to certain proportion; Simulation of top-drive used to simulate the process of top-drive drive drill pipe; Simulated down hole used to simulate the bottom hole rock; Circulating water tank is used to implement the separation of metal particles and debris. The experiment adopted high density of granite as the rock sample, the size is $250 \mathrm{~mm} * 250 \mathrm{~mm} * 250 \mathrm{~mm}$, the material is Q235 particles. 


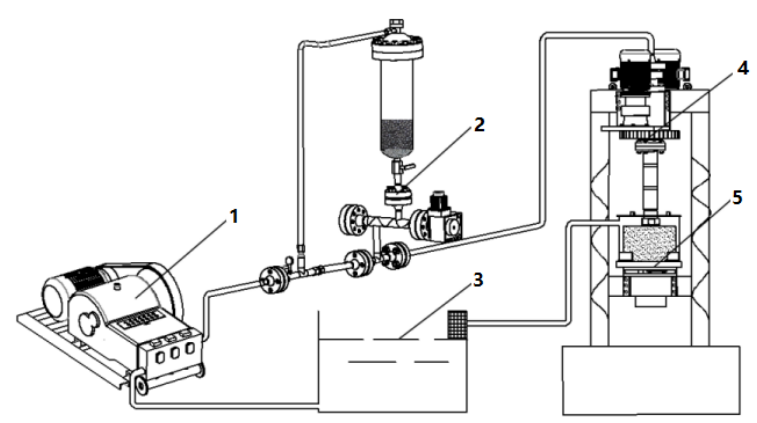

1 - high pressure mud pump; 2 - particle mixing device; 3 - water tank; 4 - simulation of top drive; 5 - simulated downhole

Figure 1. Structure diagram of test device

\section{Particle stream acceleration process modeling}

\section{The force analysis of particles and fluid in the pipe}

In the process of particle impact drilling, particles by the water jet force and its own gravity in the flow field, it include viscous resistance, added mass force and pressure gradient force.

$F_{d}$ is viscous resistance of particle in the fluid, can be expressed as:

$$
F_{d}=C_{D} \frac{\pi D_{p}^{2}}{8} \rho_{f}\left(u_{f}-u_{p}\right)^{2}
$$

Where ${ }^{D_{p}}$ is particle diameter; ${ }^{\rho_{f}}$ is fluid density; ${ }^{u_{p}}$ is the velocity of particles $;{ }^{u_{f}}$ is the velocity of water; $C_{D}$ is viscous drag coefficient, because Reynolds number of the fluid between $10^{3}$ and $10^{5}$, So $C_{D}=0.45$.

$F_{m}$ is added mass force of particle in fluid, in the process of particle acceleration, causing the fluid acceleration force is:

$$
F_{m}=\frac{1}{2} \frac{\pi D_{p}^{3} \rho_{f}}{6}\left(\frac{d u_{f}}{d t}-\frac{d u_{p}}{d t}\right)
$$

$F_{p}$ is pressure gradient force, which is a kind of force caused by the pressure gradient in flow field:

$$
F_{p}=\frac{\pi D_{p}^{3} \rho_{f}}{6} \frac{d u_{f}}{d t}
$$

\section{The particle acceleration equation in water}

From particle impact drilling dynamics analysis, particle through screw propeller into high pressure pipeline, liquid and particle interaction eventually reach a dynamic balance, the particle uniform distribution in the fluid. Force of the straight tube is viscous force and the added mass force, application of Newton's second law to establish equation of motion:

$$
m_{p} \frac{d u_{p}}{d t}=F_{d}+F_{m}
$$

Substituting (1) and (2) into (4), we can obtain:

$$
m_{p} \frac{d u_{p}}{d t}=C_{D} \frac{\pi D_{p}^{2}}{8} \rho_{f}\left(u_{f}-u_{p}\right)^{2}+\frac{\pi D_{p}^{3} \rho_{f}}{12}\left(\frac{d u_{f}}{d t}-\frac{d u_{p}}{d t}\right)
$$


After simplified, Particles Velocity equation in water can be expressed as:

$\frac{d u_{p}}{d t}=A\left(u_{p}-u_{f}\right)^{2}$

Where $A=\frac{3 C_{D} \rho_{f}}{D_{P}\left(4 \rho_{p}+2 \rho_{f}\right)}$.

By solving the differential equation of Eq. 6, we can get the velocity of particles in the pipeline.

\section{The acceleration equation of particle in the nozzle}

Straight cone nozzle structure as shown in Fig. 2. Particles suffer from the viscous force, the added mass force and the pressure gradient force in the cone section of straight cone nozzle. Base on Newton's second law, particle movement equation in water can be express as:

$$
m_{p} \frac{d u_{p}}{d t}=F_{d}+F_{p}+F_{m}
$$

Where; ${ }^{m}$ is the quality of the particle.

Substituting (1), (2) and (3) into (7), after simplifying, we can get the velocity equation of particles as:

$u_{p} \frac{d u_{p}}{d x}=A\left(u_{f}-u_{p}\right)^{2}+B u_{f} \frac{d u_{f}}{d x}$

Where $2 \rho_{p}+\rho_{f}$

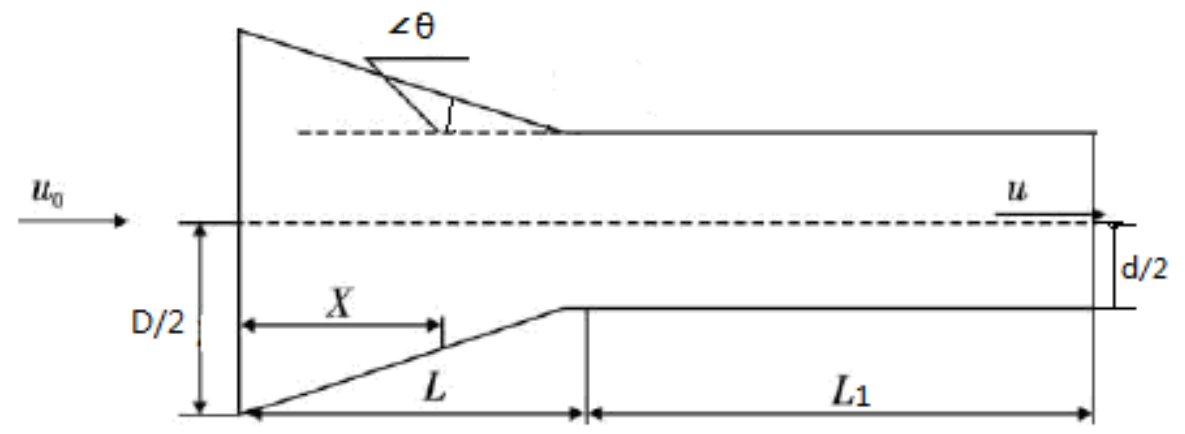

Figure 2. Straight cone nozzle

The velocity of the water in the straight section of nozzle can be calculated as:

$$
u_{f}=\frac{Q}{\pi\left(\frac{d}{2}\right)^{2}}
$$

The velocity of the water in the contraction of nozzle can be expressed as:

$$
u_{f}=u_{0}\left[\frac{D / 2}{(L-x) \tan \theta+d / 2}\right]
$$


Where ${ }^{u}$ is the speed of the water at the entrance of the nozzle; $D$ is nozzle inlet diameter; $L$ is the length of the nozzle funnel; ${ }^{d}$ is outlet diameter of the nozzle; $\theta$ is half of the nozzle contraction Angle 。

Substituting (10) into (8), we get the velocity expression form of the particles in the cone section of straight cone nozzle:

$$
\frac{d u_{p}}{d x}=\frac{A}{u_{p}}\left\{\frac{Q}{\pi}\left[\frac{1}{(L-x) \tan \theta+d / 2}\right]^{2}-u_{p}\right\}^{2}+\frac{B}{u_{p}} \frac{2 Q \tan \theta}{\pi^{2}}\left\lfloor\left.\frac{1}{(L-x) \tan \theta+d / 2}\right|^{5}\right.
$$

The velocity of particles and water in the contraction of nozzle was calculated by the Eq. 10 and 11 , the velocity of the particles in the nozzle straight section can be calculated by the following equation:

$$
u_{p} \frac{d u_{p}}{d x}=A\left(u_{f}-u_{p}\right)^{2}
$$

The velocity relationship between particles and water in nozzle shown as Fig.3. The figure reveal the velocity of particle increase linear with the water, the smaller the diameter of particles, the easier to get accelerate in the water.

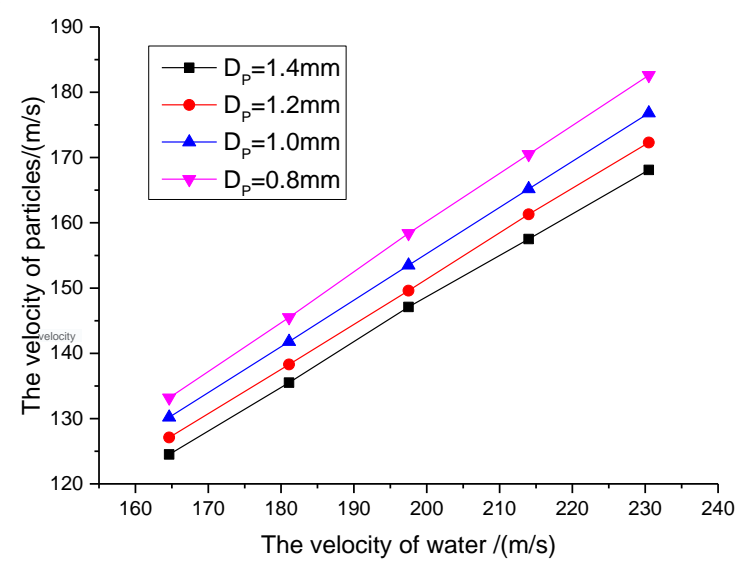

Figure 3 . The velocity relation between particle and water

\section{The particle jet flow numerical simulation}

By using FLUENT software, Choose three dimensional single precision solver, turbulent flow equation with $k-\varepsilon$ standard equation, Nozzle entry point for speed, Export is set to the discharge pressure, rock adopt the wall treatment, With the $S M P L E$ algorithm, the speed of the two phase flow are analyzed, the simulation parameters are shown in table 1, some simulation results are shown in Fig. 4.

Table 1. Simulation calculation parameter table

\begin{tabular}{|c|c|c|}
\hline setting value/material & drilling fluid & particle \\
\hline material & steel shot & concrete drilling fluid \\
\hline grain diameter D $(\mathrm{mm})$ & 1 & - \\
\hline density $\left(\mathrm{kg} / \mathrm{m}^{3}\right)$ & 1200 & 7800 \\
\hline $\left.\begin{array}{c}\mathrm{Cp} \mathrm{constant} \mathrm{pressure} \mathrm{specific} \mathrm{heat/heat} \mathrm{capacity} \\
(J /(\mathrm{kg} \cdot \mathrm{K})\end{array}\right)$ & 4500 & 460 \\
\hline coefficient of thermal conductivity $\left(\mathrm{W} /\left(\mathrm{m}^{\bullet} \mathrm{k}\right)\right.$ & 1.5 & 60 \\
\hline $\begin{array}{c}\text { dnamic viscosity/plastic viscosity }\left(\mathrm{kg} /\left(\mathrm{m}^{\bullet} \mathrm{s}\right)\right. \\
\text { volume occupied }\end{array}$ & $\varphi_{600}-\varphi_{300} \approx 0.02$ & default $1.7 \mathrm{e}-05$ \\
\hline
\end{tabular}




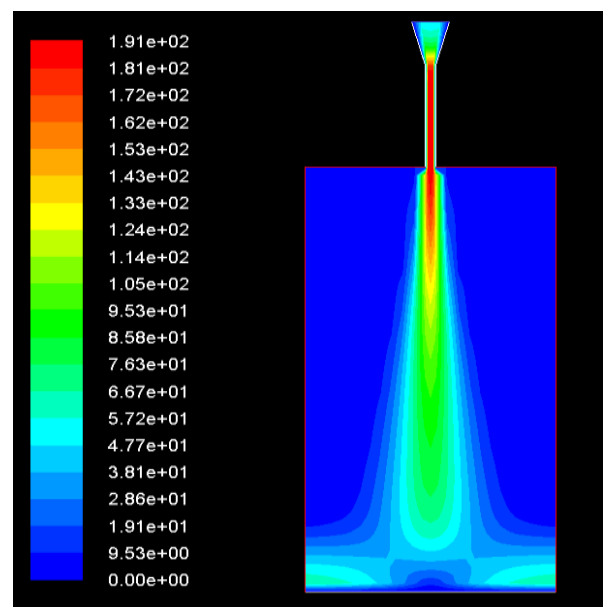

fluid velocity

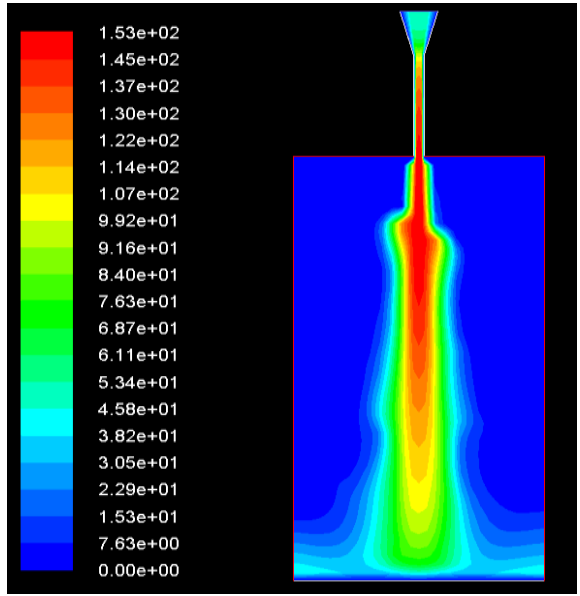

(b) particle velocity

Figure 4. Fluid and particle velocity

The simulation results show that, as shown in Fig. 5 particles and water velocity is the same as the simulation results by FLUENT software, verifies the correctness of the mathematical modeling and calculating model.

\section{Conclusions}

This paper introduces break mechanism of the particle jets coupling shock rock and the structure and function of experiment; Analyzed the influence factors of particles in the fluid acceleration; Velocity model in a straight cone nozzle of the fluid and particle was established and calculated; using Fluent software simulation software, simulation verification was performed for the acceleration of particles and fluid in a straight cone nozzle. The calculation results were identical to the simulation results. It proved the mathematical model is correct. The results can be used to determine rock parameters for particle jet impact.

\section{Acknowledgement}

The authors would like to acknowledge financial support by the New Century Excellent Talent Training Fund of Heilongjiang Province in China, Project: 1254-NCET-005 and Postdoctoral Scientific Research Development Fund of Heilongjiang Province in China, Project: LBH-Q15018.

\section{References}

[1] REN Fushen, MA Ruoxu, CHENG Xiaoze, et al, Research progress and key problems of particle impact drilling technology, Oil Field Equipment. 2014, 43 (7) 20-25.

[2] Particle Drilling Technologies Inc. Impact excavation system and method with particle separation: U.S. Patent 7,383,896. (2008)

[3] Zeng J, Kim T J, A study of brittle erosion mechanism applied to abrasive waterjet processes, 10th International Symposium on Jet Cutting Techno logy, Amsterdam, Netherlands, 1990.

[4] Fairhurst R M, Abrasive waterjet cutting, Durham, UK: Cranfield Institute of Technology, 1986.

[5] YANG Guo-lai, ZHOU Wei-hui, LIU Fei, Simulation of flow field of high pressure water-jet from nozzle with FLUENT, Journal of Lanzhou University of Technology. 2008, 34(2) 49-52.

[6] REN Fushen, LI Yang, CHENG Xiaoze, et al, Test device development of particles jet impinging on rock, Oil Field Equipment. 2016, 45(10) 49-53. 